\title{
Partially replacing cornstarch in a high- concentrate diet with sucrose inhibited the ruminal trans-10 biohydrogenation pathway in vitro by changing populations of specific bacteria
}

\author{
Xiaoqin Sun ${ }^{1}$, Yaping Wang ${ }^{1}$, Bo Chen ${ }^{1}$ and Xin Zhao ${ }^{1,2^{*}}$
}

\begin{abstract}
Background: The positive influence of replacing dietary starch with sugar on milk fat production has been proposed to be partially attributed to the inhibition of the rumen trans-10 biohydrogenation pathway. However, whether and how sucrose inhibits the rumen trans-10 biohydrogenation pathway remains elusive.

Results: A batch in vitro incubation system was used to evaluate effects of replacing cornstarch in a high-concentrate diet (forage to concentrate ratio $=40: 60$ ) with 0 (control), 3, 6 and $9 \%$ of sucrose on rumen fermentation pattern, fatty acid (FA) biohydrogenation pathways and bacterial populations relating to trans-11 to trans-10 biohydrogenation pathways. Replacing dietary cornstarch with sucrose did not alter rumen pH or concentrations of total volatile fatty acids (VFA) in comparison with the control but significantly influenced the profiles of individual VFA. The molar proportions of butyrate and valerate were linearly increased, while that of acetate was quadratically decreased and those of propionate, isobutyrate and isovalerate were linearly decreased with increasing concentrations of sucrose in the diet. Furthermore, replacing cornstarch with sucrose led to a linear decrease in C18:1 trans-10, linear increases in the proportions of $\mathrm{C} 18: 1$ trans-11, $\mathrm{C} 18: 2 \mathrm{n}-6$ and the ratio of trans-11 to trans-10, and linear decreases in biohydrogenation of C18:2n-6 and C18:3n-3. The abundance of Butyrivibrio fibrisolvens, a butyrate and CLA cis-9, trans-11 producer, was increased with the increasing inclusion of sucrose in the diet, while the population of Megasphaera elsdenii, a CLA trans-10, cis-12 producer, was significantly decreased by all levels of sucrose replacements.

Conclusions: These results indicate that replacing starch in a high-concentrate diet with sucrose increased butyrate production and inhibited the rumen trans-10 biohydrogenation pathway, which was at least partially due to increased abundance of Butyrivibrio fibrisolvens and decreased abundance of Megasphaera elsdenii.
\end{abstract}

Keywords: Bacterial populations, Cornstarch, Rumen fermentation, Sucrose, trans-10 shift

\section{Background}

Feeding high-concentrate diets is a commonly used strategy to increase energy intake and support high milk yield in the intensive dairy production system. However, it is also a well-known factor inducing rumen acidosis and milk fat depression (MFD). In order to maintain

\footnotetext{
* Correspondence: zhaoxin@nwsuaf.edu.cn

'College of Animal Science and Technology, Northwest A \& F University, Yangling, Shaanxi 712100, People's Republic of China

2Department of Animal Science, McGill University, 21,111 Lakeshore, Ste. Anne de Bellevue, QC H9X 3V9, Canada
}

animal energy intake and simultaneously reduce the risks of rumen acidosis and MFD, sugar has been used as an alternative energy source. Partially replacing dietary starch or corn grain with sugar did not decrease rumen $\mathrm{pH}$ in several studies $[1,2]$ or even increased rumen $\mathrm{pH}$ in others [3]. More importantly, feeding sugar improved milk fat content and milk fat yield [3, 4]. However, the action mechanism for the observed results is not well understood. For example, it is not known why feeding sugar potentially increases rumen $\mathrm{pH}$ despite its 
rapid rumen fermentation relative to starch. One plausible reason could be increased production of butyrate by sugar fermentation. However, effects of sugar addition on profiles of rumen volatile fatty acids (VFA) have been considerably variable. Most in vitro studies reported increased production of butyrate by including sugar in the diet $[2,5,6]$. As for in vivo studies, some reported increased butyrate concentrations by sugar-feeding $[1,3]$, while others showed no influence on concentrations of acetate, propionate, butyrate [7] or all individual VFA $[4,8]$. Concentrations of VFA in the rumen reflect a balance between acid production and disappearance. Actual production of butyrate in the rumen is likely underestimated under in vivo conditions [9], due to the faster absorption rate of butyrate than those of acetate and propionate. Thus, in vitro studies might better reflect the actual fermentation characteristics of sugarcontaining diets.

The positive influence of sugar on milk fat has been proposed to be partially attributed to inhibition of the rumen trans-10 biohydrogenation pathway [3, 9]. Occurrence of MFD induced by high-concentrate diets is known to be associated with the shift of rumen biohydrogenation pathways from trans-11 to trans-10 [10], which produce trans-10 fatty acids (FA), specifically C18:1 trans-10 and CLA trans-10,cis-12 at the expense of C18:1 trans-11 and CLA cis-9,trans-11. However, direct investigation of sugar on rumen biohydrogenation of FA is limited.

Variations in rumen VFA production and biohydrogenation of FA are associated directly with rumen microflora. However, influence of sugar on rumen microbial populations has not been extensively studied. The lactate-producing (Streptococcus bovis, S. bovis) or utilizing bacteria (Megasphaera elsdenii, M. elsdenii; Propionibacterium acnes, $P$. acnes) that proliferate in the rumen of animals receiving high-concentrate diets are major CLA trans-10, cis-12 producers [11-13]. In contrast, the well known CLA cis-9,trans-11 producer [14, 15], Butyrivibrio fibrisolvens (B. fibrisolvens), is very sensitive to high-starch diets and its population in the rumen declined considerably with concentrate feeding [16]. It is likely that replacing dietary starch with sugar could inhibit the proliferating of the CLA trans-10, cis-12 producers, reducing the production of the antilipogenic transFA and consequently improving milk fat synthesis. Unfortunately, no study, to the best of our knowledge, has investigated the effect of sugar feeding on rumen microbial community, especially the species related to rumen trans-11 to trans-10 biohydrogenation pathways.

The objective of the current in vitro study, therefore, was to evaluate the responses of partially replacing cornstarch in a high-concentrate diet with sucrose on rumen fermentation, biohydrogenation of FA and bacterial populations related to the rumen trans-10 shift.

\section{Methods}

\section{Experimental design}

A completely random design was used in an in vitro batch incubation system. Cornstarch in a basal diet (Table 1) with a concentrate to forage rate of 60:40 was replaced by four levels of sucrose: 0 (control), 3, 6 and $9 \%$ of dry matter (DM).

\section{In vitro incubation and sampling}

The batch incubation was carried out with $1.0 \mathrm{~g}$ of the four experimental diets with $30 \mathrm{~mL}$ of buffer [17] and $30 \mathrm{~mL}$ of rumen fluid at $39{ }^{\circ} \mathrm{C}$, shaking at $165 \mathrm{rpm}$. The rumen fluid was collected from four ruminally-cannulated dairy goats before morning feeding. The whole procedure was kept under strict anaerobic conditions by gassing the buffer with $\mathrm{CO}_{2}$ and using resazurin as a redox indicator, flushing the rumen fluid during handling with $\mathrm{CO}_{2}$, and gassing the headspace of incubation bottles before sealing with $\mathrm{CO}_{2}$ as well. Samples from each treatment at $0 \mathrm{~h}$ incubation were frozen and freeze-dried for FA analyses and biohydrogenation calculation. The incubation periods

Table 1 Ingredients and chemical composition of the basal diet (DM basis)

\begin{tabular}{|c|c|}
\hline Ingredient & Content, $\%$ \\
\hline Alfalfa hay & 14.50 \\
\hline Corn silage & 25.50 \\
\hline Corn & 28.20 \\
\hline Soybean meal & 18.60 \\
\hline Cornstarch & 9.00 \\
\hline Corn gluten meal & 2.50 \\
\hline Sodium bicarbonate & 0.40 \\
\hline Mineral and vitamin premix ${ }^{1}$ & 0.20 \\
\hline Dicalcium phosphate & 0.20 \\
\hline Limestone & 0.46 \\
\hline Salt & 0.44 \\
\hline \multicolumn{2}{|l|}{ Chemical composition (\% DM) } \\
\hline Organic matter & 94.3 \\
\hline Crude protein & 15.5 \\
\hline Non fiber carbohydrates ${ }^{2}$ & 49.9 \\
\hline Neutral detergent fibre & 25.1 \\
\hline Acid detergent fibre & 16.6 \\
\hline Starch & 38.7 \\
\hline Sugar & 3.96 \\
\hline
\end{tabular}

'Providing Mn 63 mg, Zn 4,640 mg, Fe 972 mg, Cu 265 mg, Se 155 mg, I $251 \mathrm{mg}$, Co $57 \mathrm{mg}$, nicotinic acid $450 \mathrm{mg}$, VE $800 \mathrm{mg}$, VD $450 \mathrm{KIU}$ and VA 1,860 KIU per kilogram

${ }^{2}$ Calculated by $100-(\%$ crude protein $+\%$ ether extract $+\%$ neutral detergent fibre) 
were set for 6, 12 and $24 \mathrm{~h}$, four replicates per treatment at each time point. At the end of $6 \mathrm{~h}$ incubation, $\mathrm{pH}$ was measured immediately and fermentation was stopped on ice. Samples for VFA (3 mL), ammonia-N (2 mL) and rumen bacterial populations $(1 \mathrm{~mL})$ were individually collected. One $\mathrm{mL}$ of $25 \%$ meta phosphoric acid was added to VFA samples, while 2 to 3 drops of $25 \%$ sulphuric acid was added to ammonia- $\mathrm{N}$ samples. These samples were stored at $-20{ }^{\circ} \mathrm{C}$ until analyses. Samples for bacterial determination were centrifuged at $20,000 \times \mathrm{g}\left(4^{\circ} \mathrm{C}\right)$ for 5 min immediately after collection and the pellets were stored at $-80{ }^{\circ} \mathrm{C}$. Residues in the incubated bottles were frozen, freeze-dried, weighed and stored at $-20{ }^{\circ} \mathrm{C}$ for FA analyses. After 12 and $24 \mathrm{~h}$ incubation, samples were collected for rumen bacterial population determination.

\section{Chemical analysis}

Nitrogen, DM, acid detergent fibre, ether extract and ash in the basal diet were analyzed according to the methods described by AOAC [18]. Crude protein was determined by multiplying nitrogen by 6.25 . Neutral detergent fibre was assayed with a heat stable $\alpha$-amylase and sodium sulfite according to Van Soest et al. [19], expressed inclusive of residual ash. Non structural carbohydrate was calculated by $100-(\%$ crude protein $+\%$ ether extract $+\%$ neutral detergent fibre). Starch was analyzed according to the enzymatic-colorimetric method [20]. Sugar was extracted with ethanol/water solution $(\mathrm{v} / \mathrm{v}=80: 20)$ and followed by the phenolsulphuric acid assay [21].

Samples for VFA and ammonia-N analyses were thawed, centrifuged at $20,000 \times \mathrm{g}$ for $20 \mathrm{~min}$ at $4{ }^{\circ} \mathrm{C}$, and supernatant filtered through a $0.45 \mu \mathrm{m}$ syringe filter were used for analysis. The pellets were freeze-dried and weighed for biohydrogenation estimation. VFA was determined by gas chromatography (GC-7890, Agilent Technologies, Hewlett Packard Co., Avondale, PA) fitted with a flame-ionization detector using a $30 \mathrm{~m} \times 0.25 \mathrm{~mm} \times$ $0.33 \mu \mathrm{m}$ fused silica column (AE-FFAP; Atech Technologies Co. Ltd., Taipei, Taiwan, China) according to Khorasani et al. [22]. Ammonia-N was determined by colorimetry as described by Fawcett and Scott [23].

The composition of FA was analyzed as described by Sun and Gibbs [24]. Briefly, the freeze-dried samples were directly methylated with $4 \mathrm{~mL}$ of $0.5 \mathrm{~mol} / \mathrm{L} \mathrm{NaOH} /$ methanol $\left(15 \mathrm{~min}\right.$ at $\left.50{ }^{\circ} \mathrm{C}\right)$ followed by $4 \mathrm{~mL}$ of $5 \% \mathrm{HCl} /$ methanol $\left(1 \mathrm{~h}\right.$ at $\left.50{ }^{\circ} \mathrm{C}\right)$, extracted with $2 \mathrm{~mL}$ of heptane and then introduced to the GC equipped with a fused silica capillary column (SP-2560, $100 \mathrm{~m} \times 0.25 \mathrm{~mm} \times 0.2 \mu \mathrm{m}$; Supelco Inc., Bellefonte, PA). Nitrogen was used as the carrier gas. The split ratio was 50:1, and the injector and detector were held at $250{ }^{\circ} \mathrm{C}$. The temperature gradient was $166^{\circ} \mathrm{C}$ for $39 \mathrm{~min}$, increased by $10.0{ }^{\circ} \mathrm{C} / \mathrm{min}$ to $240{ }^{\circ}$ $\mathrm{C}$, held for $10 \mathrm{~min}$, increased by $3.0^{\circ} \mathrm{C} / \mathrm{min}$ to $245^{\circ} \mathrm{C}$, and held for $10 \mathrm{~min}$. C19:0 was used as an internal standard, and ME 61, ME93, BR $2, \mathrm{BR}_{3}, \mathrm{CLA}$ cis-9, trans-11 and CLA trans-10, cis-12 methyl esters were used as external standards (Larodan Fine Chemicals AB, Malmo, Sweden). Peaks of four C18:1 (trans-4, trans-5, trans-6/7/8, trans10) and six C18:2 (trans-9, trans-12, cis-9, trans-13, trans8, cis-13, cis-9, trans-12, trans-9, cis-12, trans-11, cis-15) isomers without commercial external standards were identified by the order of elution with respect to those FA with external standards and interpolation from the peaks reported [25].

Total microbial genomic DNA was extracted according to Kittelmann et al. [26]. Briefly, microbial cells were disrupted by bead-beating and microbial genomic DNA was extracted by phenol-chloroform extraction. DNA was subsequently precipitated by adding $1 / 10$ volume of $3 \mathrm{~mol} / \mathrm{L}$ sodium acetate ( $\mathrm{pH} 5.2$ ) and 2 volumes of $70 \%$ ice-cold ethanol. The precipitate was then resuspended in $100 \mu \mathrm{L}$ of an elution buffer $(10 \mathrm{mmol} / \mathrm{L}$ Tris $-\mathrm{HCl}$, $\mathrm{pH}$ 8.5). RNA was eliminated by adding $10 \mathrm{mg} / \mathrm{mL}$ of RNase A, and DNA was subsequently cleaned up using the EasyPure PCR purification kit (Transgen, China) and eluted in $50 \mu \mathrm{L}$ EB. The concentration and purity of the extracted DNA were determined by a NanoDrop spectrophotometer (Thermo Scientific, USA).

Quantitative real-time PCR was performed on a CFX96 Real-Time PCR Detection System (Bio-Rad, USA) to investigate the abundance of $B$. fibrisolvens, $S$. bovis, $M$. elsdenii and $P$. acnes as described by Li et al. [27]. Briefly, a $25-\mu \mathrm{L}$ PCR mixture was prepared using $12.5 \mu \mathrm{L}$ of SYBR Premix Ex TaqII (TAKARA, China), $1 \mu \mathrm{L}$ of forward primer $(10 \mu \mathrm{mol} / \mathrm{L}), 1 \mu \mathrm{L}$ of reverse primer $(10 \mu \mathrm{mol} / \mathrm{L}), 1 \mu \mathrm{L}$ of DNA, and $9.5 \mu \mathrm{L}$ of doubledistilled water. The thermal cycling parameters were programmed at $95{ }^{\circ} \mathrm{C}$ for $30 \mathrm{~s}$ for initial denaturation, 40 cycles of $95{ }^{\circ} \mathrm{C}$ for $5 \mathrm{~s}$, and $60{ }^{\circ} \mathrm{C}$ for $30 \mathrm{~s}$ for primer annealing and product elongation. Fluorescence detection was performed at the end of each extension step. The 16S rRNA gene-targeted primer sets are listed in Table 2. Samples were run as triplicate. Amplicon specificity was determined via melt curve analysis of PCR end products by raising the temperature at the rate of $1{ }^{\circ} \mathrm{C}$ per $30 \mathrm{~s}$ from 60 to $95{ }^{\circ} \mathrm{C}$. The population sizes of specific bacterial groups were expressed as a percentage relative to the abundance of the general bacterial $16 \mathrm{~S}$ rRNA gene.

\section{Calculation and statistical analysis}

Biohydrogenation of C18:2n-6 and C18:3n-3 was estimated based on disappearance of these fatty acids from $0 \mathrm{~h}$ incubation to the end of incubation. Total weights of the residues after incubation were estimated by summing up the freeze-dried weights of contents in the incubation bottles and those pellets from VFA and ammonia-N samples. 
Table 2 Primers used for real-time PCR

\begin{tabular}{llll}
\hline Target species & Primer & Sequence $\left(5^{\prime} \rightarrow 3^{\prime}\right)$ & Reference \\
\hline General bacteria & Forward & CGGCAACGAGGCAACCC & McSweeney and Denman [41] \\
Butyrivibrio fibrisolvens & Reverse & CCATGTAGCACGTGTGTAGCC & Stevenson and Weimer [42] \\
Streptococcus bovis & Forward & ACCGCATAAGCGCACGGA & Stevenson and Weimer [42] \\
& Reverse & CGGGTCCATCTTGTACCGATAAAT & Stevenson and Weimer [42] \\
Megasphaera elsdenii & Forward & TTCCTAGAGATAGGAAGTTCTTCGG & Shingfield et al. [43] \\
& Foverse & ATGATGGCAACTAACAATAGGGGT & \\
\hline
\end{tabular}

Data were analyzed using One-way ANOVA of SPSS17.0 (SPSS software for Windows, release 17.0, SPSS Inc., Chicago, IL). Tukey's test was used for multiple comparisons, and orthogonal polynomials were used to test linear and quadratic responses for increasing levels of sucrose in the diet. Significance was declared at $P<0.05$.

\section{Results}

\section{Rumen fermentation}

As shown in Table 3, replacing dietary cornstarch with 3 to $9 \%$ of sucrose had no significant influence on rumen $\mathrm{pH}(P=0.971)$ and total VFA concentrations $(P=0.056)$ after $6 \mathrm{~h}$ in vitro incubation. However, the profiles of individual VFA were affected significantly $(P<0.05)$ by sucrose treatment. The molar proportion of acetate decreased quadratically $(P<0.001)$, while those of propionate, isobutyrate and isovalerate decreased linearly $(P<0.001)$ as the inclusion of sucrose increased. The molar proportion of butyrate increased quadratically $(P<0.001)$ with increasing sucrose addition, while the molar proportion of valerate increased linearly $(P=0.002)$. Concentrations of ammonia$\mathrm{N}$ decreased linearly $(P<0.001)$ with the inclusion of sucrose.

\section{Fatty acids composition and biohydrogenation}

Effects of replacing dietary cornstarch with sucrose on FA composition and biohydrogenation after $6 \mathrm{~h}$ in vitro incubation were presented in Tables 4 and 5. Sucrose inclusion had no effect $(P>0.05)$ on the proportions of the medium-chain FA and long-chain saturated FA (Table 4). However, the proportions of some C18 FA isomers were influenced $(P<0.05)$ (Table 5$)$. For $C 18: 1$ isomers, the proportions of C18:1 trans-5, C18:1 trans-10 and C18:1 trans-11 were affected significantly $(P<0.05)$ by dietary treatments. C18:1 trans-10 decreased linearly $(\mathrm{P}<0.05)$ while C18:1 trans-11 increased linearly $(P<0.05)$ with the increasing inclusion of sucrose. For the two major dietary poly-unsaturated FA, the proportion of C18:2 n-

Table 3 Rumen pH, volatile fatty acid (VFA) profiles and ammonia-N concentration after $6 \mathrm{~h}$ in vitro incubation

\begin{tabular}{|c|c|c|c|c|c|c|c|c|}
\hline \multirow[t]{2}{*}{ Item } & \multicolumn{4}{|c|}{ Sucrose level } & \multirow[t]{2}{*}{$\mathrm{SEM}^{1}$} & \multicolumn{3}{|c|}{$P$-value ${ }^{2}$} \\
\hline & 0 & $3 \%$ & $6 \%$ & $9 \%$ & & $\mathrm{~T}$ & $L$ & Q \\
\hline Rumen pH & 6.17 & 6.17 & 6.18 & 6.19 & 0.014 & 0.971 & 0.641 & 1.000 \\
\hline Total VFA, mmol/L & 73.8 & 74.8 & 75.9 & 76.5 & 0.391 & 0.056 & 0.009 & 0.738 \\
\hline \multicolumn{9}{|c|}{ Individual VFA (mol/100 mol) } \\
\hline Acetate & $63.0^{\mathrm{a}}$ & $62.8^{\mathrm{b}}$ & $62.7^{b}$ & $63.1^{\mathrm{a}}$ & 0.044 & 0.003 & 0.380 & $<0.001$ \\
\hline Propionate & $20.4^{a}$ & $20.1^{b}$ & $19.9^{\mathrm{bc}}$ & $19.7^{c}$ & 0.074 & 0.001 & $<0.001$ & 0.324 \\
\hline Butyrate & $12.2^{c}$ & $12.7^{\mathrm{b}}$ & $13.1^{\mathrm{a}}$ & $12.9^{\mathrm{ab}}$ & 0.090 & $<0.001$ & $<0.001$ & $<0.001$ \\
\hline Isobutyrate & $1.16^{\mathrm{a}}$ & $1.14^{\mathrm{b}}$ & $1.11^{\mathrm{C}}$ & $1.08^{\mathrm{d}}$ & 0.009 & $<0.001$ & $<0.001$ & 0.715 \\
\hline Valerate & $1.25^{\mathrm{b}}$ & $1.29^{\mathrm{ab}}$ & $1.30^{a}$ & $1.31^{\mathrm{a}}$ & 0.008 & 0.015 & 0.002 & 0.457 \\
\hline Isovalerate & $2.07^{a}$ & $2.01^{b}$ & $1.95^{c}$ & $1.89^{d}$ & 0.018 & $<0.001$ & $<0.001$ & 0.804 \\
\hline$A: P$ ratio $^{3}$ & $3.09^{c}$ & $3.12^{b c}$ & $3.16^{\mathrm{ab}}$ & $3.19^{a}$ & 0.012 & 0.002 & $<0.001$ & 0.987 \\
\hline Ammonia, mg/dL & $28.9^{a}$ & $27.5^{\mathrm{b}}$ & $26.8^{\mathrm{b}}$ & $26.6^{b}$ & 0.291 & 0.005 & $<0.001$ & 0.114 \\
\hline
\end{tabular}

Note: Means within the same row with different superscripts differ significantly $(P<0.05)$

${ }^{1} \mathrm{SEM}=$ standard error of mean

${ }^{2}$ Probability of a significant effect of treatment $(\mathrm{T})$, or linear $(\mathrm{L})$ and quadratic $(\mathrm{Q})$ orthogonal contrasts for dietary sucrose levels

${ }^{3} \mathrm{~A}: \mathrm{P}$ ratio = acetate to propionate ratio 
Table 4 Composition of the medium- and long-chain fatty acid (FA) after $6 \mathrm{~h}$ in vitro incubation

\begin{tabular}{|c|c|c|c|c|c|c|c|c|}
\hline \multirow{2}{*}{$\begin{array}{l}\text { Fatty acid, \% of } \\
\text { total FA }\end{array}$} & \multicolumn{4}{|c|}{ Sucrose level } & \multirow[t]{2}{*}{ SEM $^{1}$} & \multicolumn{3}{|c|}{$P$-value ${ }^{2}$} \\
\hline & $\overline{0}$ & $3 \%$ & $6 \%$ & $9 \%$ & & $\overline{\mathrm{T}}$ & $\mathrm{L}$ & Q \\
\hline $2: 0$ & 0.48 & 0.58 & 0.42 & 0.67 & 8 & 0.507 & 0.456 & 0.563 \\
\hline $13: 0$ ar & 0.36 & 0.25 & 0.34 & 0.29 & 0.024 & 0.409 & 0.569 & 0.622 \\
\hline 3:0 & 0. & 0.18 & 0.26 & 0.23 & 0.015 & 0.324 & 0.321 & 0 \\
\hline 14:0 i & 0.71 & 0.57 & 0.56 & 0.69 & 0.033 & 0.214 & 0.825 & 0.044 \\
\hline 14:0 & 2 & 2.28 & 2.19 & 2.62 & 0.090 & 0.218 & 0.879 & 0 \\
\hline $14: 1$ trans-9 & 2.21 & 1.83 & 2.12 & 2.19 & 0.087 & 0.367 & 0.783 & 0.209 \\
\hline 15:0 & 3.12 & 2.53 & 2.33 & 3.15 & 167 & 0.228 & 0.946 & 0.047 \\
\hline $14: 1$ & 1.85 & 1.61 & 1.42 & 1.65 & 0.073 & 0.271 & 0.219 & 0.122 \\
\hline C15:0 & 1.23 & 1.02 & 1.11 & 1.40 & 0.078 & 0.333 & 0.375 & 0.124 \\
\hline $16: 0 \mathrm{i}$ & 1.22 & 1.04 & 1.01 & 1.12 & 0.040 & 0.126 & 0.785 & 0.022 \\
\hline 16:0 & 27.6 & 25.1 & 25.8 & 26.1 & 0.492 & 0.294 & 0.366 & 0.158 \\
\hline 10.1 & 0.53 & 0.49 & 6 & 8 & 1 & 0 & 0.395 & 0 \\
\hline 17:0 an & 1.47 & 1.24 & 1.15 & 1.50 & 0.073 & 0.271 & 0.982 & 0.060 \\
\hline 16:1cis & 0.69 & 068 & 0.63 & 0.80 & 0.034 & 0.391 & 0.358 & 0.2 \\
\hline C17:0 & 0.58 & 0.63 & 0.53 & 0.61 & 0.018 & 0.251 & 0.958 & 0.630 \\
\hline 8. & 0.05 & 0.06 & 0.12 & 0.11 & 15 & 0.261 & 0.077 & 0.896 \\
\hline $\mathrm{C} 20: 0$ & 0.45 & 0.53 & 0.47 & 0.55 & 0.021 & 0.229 & 0.151 & 1.000 \\
\hline C20:1 trans-11 & 0.19 & 0.20 & 0.21 & 0.20 & 0.007 & 0.771 & 0.576 & 0.396 \\
\hline C22:1 trans-13 & 0.04 & 0.05 & 0.05 & 0.05 & 0.004 & 0.470 & 0.225 & 0.526 \\
\hline C24:0 & 0.36 & 0.60 & 0.50 & 0.65 & 0.051 & 0.176 & 0.089 & 0.648 \\
\hline $\mathrm{C} 26: 0$ & 0.13 & 0.18 & 0.14 & 0.20 & 0.020 & 0.632 & 0.388 & 0.909 \\
\hline
\end{tabular}

${ }^{1}$ SEM standard error of mean

2 Probability of a significant effect of treatment $(T)$, or linear $(L)$ and quadratic (Q) orthogonal contrasts for dietary sucrose levels

6 was influenced $(P<0.05)$ by inclusion of sucrose, while proportion of $\mathrm{C} 18: 3 \mathrm{n}-3$ was not affected $(P>0.05)$ by the dietary treatment. The ratio of trans-11 to trans -10 was linearly increased $(P>0.05)$ by increasing inclusion of sucrose in the diet. Biohydrogenation of C18:2 n-6 and C18:3 n-3 both decreased linearly $(P<0.05)$ by increasing inclusion of sucrose.

\section{Bacterial populations}

Replacing dietary cornstarch with sucrose did not influence $(P>0.05)$ the numbers of $B$. fibrisolvens, $M$. elsdenii, S. bovis or $P$. acnes after 6 and $12 \mathrm{~h}$ incubations (Table 6). Results from $24 \mathrm{~h}$ incubation indicated that sucrose inclusion linearly increased $(P=0.005)$ the abundance of $B$. fibrisolvens, whose numbers were greater $(P<0.05)$ in the 6 and $9 \%$ sucrose treatments in comparison with the control and the $3 \%$ treatment. The numbers of $M$. elsdenii after $24 \mathrm{~h}$ incubation were lower $(P<0.05)$ in three sucrose treatments compared to the control diet, however, no difference $(P>0.05)$ was observed among these treatments. The $3 \%$ sucrose treatment had greater $(P<0.05) S$. bovis populations than other treatments after $24 \mathrm{~h}$ incubation. However, the numbers of $P$. acnes were not affected $(P=0.227)$ by sucrose treatments even after $24 \mathrm{~h}$ incubation. The changing patterns of the measured bacterial groups were similar among 4 treatment groups, with the numbers of $B$. fibrisolvens, $S$. bovis and P. acnes increased and the number of $M$. elsdenii decreased over the time. However, sucrose inclusion caused larger changes than the control treatment.

\section{Discussions}

Results of the current study showed significant influences on all individual VFA by partially replacing dietary cornstarch with sucrose, with the molar proportions of butyrate and valerate were significantly increased $(P<0.05)$, while those of acetate, propionate, isobutyrate and isovalerate were significantly decreased $(P<0.01)$. This variation pattern was quite similar to the previous in vitro $[2,6]$ and in vivo [28] studies, except that the molar proportion of propionate was not affected in the study of Ribeiro et al. [6], while valerate was linearly reduced with the increasing level of dietary sucrose in the study of Vallimont [2]. The increased molar proportion of butyrate observed in the present study was consistent to the earlier in vitro $[2,6]$ and in vivo [3,29] studies, confirming that fermentation of sucrose in place of starch increased butyrate production. Ribeiro et al. [6] suggested that the greater butyrate concentration could be attributed to a change in fermentation pathways to accommodate the higher flux of hydrogen from the rapidly fermented sugar source or the synthesis of this acid from lactate by $M$. elsdenii. In our study, the numbers of $M$. elsdenii were lower $(P<0.05)$ in three sucrose treatments after $24 \mathrm{~h}$ incubation compared to the control diet and it seems that M. elsdenii was not responsible for increased butyrate production. Instead, abundance of B. fibrisolvens increased after $24 \mathrm{~h}$ incubation, which might be at least partially responsible for increased butyrate production. Doubling ruminal butyrate concentrations by ruminal infusion of butyrate increased the relative abundance of $B$. fibrisolvens by $65 \%$ [30]. In addition, oral administration of $B$. fibrosolvens in mice resulted in a significant increase in the rate of fecal butyrate production [31]. Butyrate is one of the major precursors of milk fat and increase of this acid may help explain the increased milk fat production observed in sugar feeding studies in vivo $[3,8]$.

The reduced production of branched-chain VFA (isobutyrate and isovalerate) found in the present study was consistent with the earlier studies [1, 6, 7], suggesting the deamination and decarboxylation of branched-chain amino acid formation system might be reduced by sucrose fermentation, because this is the producing 
Table 5 C18 fatty acids (FA) composition and biohydrogenation of C18:2 n- 6 and C18:3 n-3 after 6 h in vitro incubation

\begin{tabular}{|c|c|c|c|c|c|c|c|c|}
\hline \multirow[t]{2}{*}{ Fatty acid, $\%$ of total FA } & \multicolumn{4}{|c|}{$\underline{\text { Sucrose level }}$} & \multirow[t]{2}{*}{ SEM $^{1}$} & \multicolumn{3}{|c|}{$P$-value ${ }^{2}$} \\
\hline & 0 & $3 \%$ & $6 \%$ & $9 \%$ & & $\mathrm{~T}$ & $\mathrm{~L}$ & Q \\
\hline C18:0 & 22.6 & 23.2 & 19.3 & 17.7 & 1.146 & 0.252 & 0.071 & 0.620 \\
\hline C18:1 trans- 4 & 0.13 & 0.20 & 0.17 & 0.18 & 0.011 & 0.150 & 0.204 & 0.197 \\
\hline C18:1 trans -5 & $0.17^{\mathrm{a}}$ & $0.11^{\mathrm{b}}$ & $0.15^{\mathrm{a}}$ & $0.14^{\mathrm{ab}}$ & 0.008 & 0.017 & 0.256 & 0.064 \\
\hline C18:1 tans $-6 / 7 / 8$ & 3.79 & 3.84 & 3.59 & 3.29 & 0.135 & 0.475 & 0.171 & 0.531 \\
\hline C18:1 trans-9 & 0.14 & 0.11 & 0.20 & 0.14 & 0.020 & 0.567 & 0.636 & 0.799 \\
\hline C18:1 trans-10 & $0.38^{\mathrm{a}}$ & $0.34^{\mathrm{a}}$ & $0.24^{b}$ & $0.24^{\mathrm{b}}$ & 0.021 & 0.011 & 0.002 & 0.554 \\
\hline C18:1 trans-11 & $8.70^{b}$ & $8.91^{\mathrm{b}}$ & $10.1^{\mathrm{a}}$ & $10.5^{\mathrm{a}}$ & 0.107 & 0.040 & 0.021 & 0.549 \\
\hline C18:1 cis-9 & 1.48 & 1.58 & 1.75 & 1.62 & 0.061 & 0.565 & 0.303 & 0.381 \\
\hline C18:1 cis-6 & 0.26 & 0.25 & 0.22 & 0.20 & 0.020 & 0.702 & 0.259 & 0.997 \\
\hline C18:1 cis-11 & 0.16 & 0.15 & 0.081 & 0.16 & 0.123 & 0.093 & 0.491 & 0.079 \\
\hline C18:2 trans-9, trans- 12 & 0.11 & 0.21 & 0.15 & 0.18 & 0.020 & 0.313 & 0.386 & 0.417 \\
\hline C18:2 cis-9,trans-13 & 0.058 & 0.048 & 0.061 & 0.062 & 0.004 & 0.699 & 0.542 & 0.579 \\
\hline C18:2 trans-8,cis-13 & 0.63 & 0.61 & 0.60 & 0.69 & 0.022 & 0.435 & 0.346 & 0.210 \\
\hline C18:2 cis-9,trans-12 & 0.064 & 0.058 & 0.061 & 0.078 & 0.004 & 0.303 & 0.209 & 0.168 \\
\hline C18:2 trans-9,cis-12 & 0.036 & 0.033 & 0.045 & 0.032 & 0.004 & 0.709 & 0.987 & 0.556 \\
\hline C18:2 trans-11,cis-15 & 0.14 & 0.13 & 0.12 & 0.13 & 0.011 & 0.962 & 0.922 & 0.641 \\
\hline C18:2 n-6 & $11.0^{\mathrm{b}}$ & $13.6^{\mathrm{ab}}$ & $16.4^{\mathrm{a}}$ & $14.5^{\mathrm{ab}}$ & 0.707 & 0.045 & 0.021 & 0.072 \\
\hline C18:3 n-3 & 2.34 & 3.00 & 3.11 & 2.75 & 0.114 & 0.063 & 0.131 & 0.021 \\
\hline CLA cis-9,trans-11 & 0.028 & 0.043 & 0.026 & 0.036 & 0.004 & 0.588 & 0.871 & 0.811 \\
\hline CLA trans-10,cis-12 & 0.036 & 0.033 & 0.032 & 0.029 & 0.003 & 0.894 & 0.473 & 0.985 \\
\hline Trans-11/trans- $10^{3}$ & $19.1^{c}$ & $21.2^{b c}$ & $33.7^{\mathrm{ab}}$ & $40.0^{\mathrm{a}}$ & 2.959 & 0.012 & 0.002 & 0.609 \\
\hline \multicolumn{9}{|l|}{ Biohydrogenation (\%) } \\
\hline C18:2n-6 & $58.5^{\mathrm{a}}$ & $43.8^{b}$ & $36.2^{b}$ & $36.3^{b}$ & 3.151 & 0.008 & 0.002 & 0.081 \\
\hline C18:3n-3 & $30.9^{\mathrm{a}}$ & $25.8^{\mathrm{ab}}$ & $17.4^{c}$ & $19.1^{b c}$ & 1.790 & 0.015 & 0.046 & 0.253 \\
\hline
\end{tabular}

Note: Means within the same row with different superscripts differ significantly $(P<0.05)$

1 SEM = standard error of mean

2 Probability of a significant effect of treatment $(\mathrm{T})$, or linear $(\mathrm{L})$ and quadratic $(\mathrm{Q})$ orthogonal contrasts for dietary sucrose levels

${ }^{3}$ Tans-11/trans-10 = ratio of total trans- 11 C18 isomers (C18:1 trans-11 + CLA cis-9,trans-11) to trans-10 isomers (C18:1 trans-10 + CLA trans-10, cis-12)

pathway of rumen branched-chain VFA [32]. Besides, $M$. elsdenii were capable of deaminating branched-chain amino acid and producing branched-chain VFA [33], thus, the decreased branched-chain VFA proportion observed by sugar fermentation might be partially due to reduction in the population of $M$. elsdenii in the present study.

The unaffected $(P>0.05) \mathrm{pH}$ and total VFA concentrations (Table 3) observed in the present study were consistent with the earlier findings based on sucrose replacing for starch $[1,2]$ or supplementing to alfalfa hay [6]. Our results support the suggestion that the rapid disappearance of sugar per se does not necessarily mean extensive fermentation, leading to increased acid production and low rumen $\mathrm{pH}$ [9]. To our knowledge, studies $[29,34]$ that reported decreased rumen $\mathrm{pH}$ by sucrose inclusion in the diets were not starch replacing experiments, and reasons for reduced rumen $\mathrm{pH}$ observed in those studies might be attributed to either extremely low-forage rations (only $10 \%$ of DM) [34], or extremely high sucrose amount (approximately $20 \%$ of DM) dosed to the rumen [29]. Thus, the present results indicated that replacing dietary cornstarch in a highconcentrate diet with up to $9 \%$ of sucrose might not increase the risk of rumen acidosis. Decreased proton production by increased butyrate and valerate production and less carbon provided by sucrose fermentation compared to starch [35] could be the most possible explanations for the unaffected $\mathrm{pH}$ observed in the present study. As 1 mole of hexose ferments to 1 mole of butyrate or valerate, or to 2 moles of propionate or acetate [36], the greater butyrate and valerate production in the rumen from feeding sugar would decrease proton production per unit of organic matter fermented in the rumen compared with acetate or propionate production.

To our knowledge, this is the first study investigating the effects of partially replacing dietary starch with sucrose on the rumen trans-10 shift with a high- 
Table 6 Rumen bacterial populations (\% of total bacteria) after 6, 12 and $24 \mathrm{~h}$ in vitro incubation

\begin{tabular}{|c|c|c|c|c|c|c|c|c|c|}
\hline \multirow[t]{2}{*}{ Bacteria $^{1}$} & \multirow{2}{*}{$\begin{array}{l}\text { Incubation } \\
\text { time }\end{array}$} & \multicolumn{4}{|c|}{ Sucrose level } & \multirow[t]{2}{*}{ SEM $^{2}$} & \multicolumn{3}{|c|}{$P$-value ${ }^{3}$} \\
\hline & & 0 & $3 \%$ & $6 \%$ & $9 \%$ & & $\overline{\mathrm{T}}$ & L & Q \\
\hline \multirow[t]{3}{*}{ B. fibrisolvens } & $6 \mathrm{~h}$ & 0.0013 & 0.0015 & 0.0018 & 0.0013 & 0.0007 & 0.063 & 0.580 & 0.018 \\
\hline & $12 \mathrm{~h}$ & 0.0016 & 0.0022 & 0.0023 & 0.0025 & 0.0001 & 0.142 & 0.033 & 0.480 \\
\hline & $24 \mathrm{~h}$ & $0.0017^{c}$ & $0.0020^{b c}$ & $0.0029^{a}$ & $0.0025^{\mathrm{ab}}$ & 0.0002 & 0.008 & 0.005 & 0.110 \\
\hline \multirow[t]{3}{*}{ M. elsdenii } & $6 \mathrm{~h}$ & 0.041 & 0.041 & 0.035 & 0.044 & 0.0044 & 0.927 & 0.940 & 0.683 \\
\hline & $12 \mathrm{~h}$ & 0.037 & 0.025 & 0.035 & 0.043 & 0.0039 & 0.481 & 0.415 & 0.249 \\
\hline & $24 \mathrm{~h}$ & $0.034^{\mathrm{a}}$ & $0.015^{b}$ & $0.021^{\mathrm{b}}$ & $0.018^{b}$ & 0.0026 & 0.036 & 0.049 & 0.075 \\
\hline \multirow[t]{3}{*}{ S. bovis } & $6 \mathrm{~h}$ & 0.061 & 0.060 & 0.038 & 0.044 & 0.0121 & 0.898 & 0.537 & 0.886 \\
\hline & $12 \mathrm{~h}$ & 0.090 & 0.099 & 0.080 & 0.100 & 0.0057 & 0.718 & 0.756 & 0.548 \\
\hline & $24 \mathrm{~h}$ & $0.080^{\mathrm{b}}$ & $0.18^{\mathrm{a}}$ & $0.090^{\mathrm{b}}$ & $0.11^{\mathrm{b}}$ & 0.0139 & 0.016 & 0.848 & 0.062 \\
\hline \multirow[t]{3}{*}{ P. acnes } & $6 \mathrm{~h}$ & 0.029 & 0.035 & 0.050 & 0.054 & 0.0047 & 0.190 & 0.039 & 0.956 \\
\hline & $12 \mathrm{~h}$ & 0.073 & 0.074 & 0.061 & 0.069 & 0.0046 & 0.776 & 0.561 & 0.705 \\
\hline & $24 \mathrm{~h}$ & 0.080 & 0.103 & 0.077 & 0.087 & 0.0049 & 0.227 & 0.930 & 0.463 \\
\hline
\end{tabular}

Note: Means within the same row with different superscripts differ significantly $(P<0.05)$

${ }^{1}$ B. fibrisolvens = Butyrivibrio fibrisolvens, S. bovis = Streptococcus bovis, M. elsdenii = Megasphaera elsdenii, $P$. acnes = Propionibacterium acnes

${ }^{2} \mathrm{SEM}=$ standard error of mean

${ }^{3}$ Probability of a significant effect of treatment $(\mathrm{T})$, or linear $(\mathrm{L})$ and quadratic $(\mathrm{Q})$ orthogonal contrasts for dietary sucrose levels

concentrate diet. Results of the current study demonstrated that replacing cornstarch in a high-concentrate diet with sucrose inhibited the rumen trans-10 shift by reducing C18:1 trans-10 production and increasing C18:1 trans-11 production. The variations in these two C18:1 trans isomers occurred in the absence of changes in their major C18:2 precursors, CLA trans-10, cis-12 and CLA cis-9, trans-11. The trans-11 to trans-10 ratio in rumen fluid has been considered as an indicator of changed rumen microbial populations [37]. However, although the ratio of trans-11 to trans-10 in the present study increased linearly from 19.1 to 40.0 with the increasing inclusion of sucrose in the diet after $6 \mathrm{~h}$ in vitro incubation, we failed to detect any statistical difference in the relative abundance of the four groups of bacteria after 6 or $12 \mathrm{~h}$ of incubation. Results from $24 \mathrm{~h}$ incubation showed that replacing cornstarch for sucrose substantially increased the populations of rumen CLA cis-9,trans-11 producing bacteria (B. fibrisolvens) and reduced numbers of one species (M. elsdenil) of the reported CLA trans-10, cis-12 producers. These results were in accordance with observed variations in the proportions of C18:1 trans-11 and C18:1 trans-10, indicating that the inhibition of rumen trans-10 shift by sucrose might be mainly related to a shift of these bacteria. It has been suggested that trans-10 shift could result from a dysbiosis in the rumen in favor of trans10-producing bacteria at the expense of those producing trans-11 or a modification of bacterial activities [38]. Thus, the change of rumen bacteria by sucrose addition could be due to higher activities at the beginning and higher bacterial numbers later.
As a major cellulolytic microorganism and butyrate producer in the rumen, $B$. fibrisolvens has a high affinity toward maltose and sucrose utilization [39], which could be a possible explanation for the increased number of this bacterium by sucrose inclusion in the diet. However, $B$. fibrisolvens is also a major microbe related to rumen biohydrogenation [40], and the increase of its population theoretically means greater biohydrogenation of dietary unsaturated FA. However, biohydrogenation of C18:2 n6 and C18:3 n-3 in the present study decreased linearly with increasing sucrose inclusion in the diet. Similar observation was also reported when sucrose was added to alfalfa hay [6]. Why biohydrogenation of C18:2 n-6 and C18:3 n-3 did not increase in this study warrants further investigation.

\section{Conclusions}

Replacing cornstarch in a high-concentrate diet with sucrose in vitro did not alter rumen $\mathrm{pH}$ and total VFA concentration, but increased molar proportions of butyrate and valerate. Sucrose inclusion in the diet inhibited the rumen trans-10 biohydrogenation pathway as evidenced by decreased proportion of C18:1 trans-10 and increased proportion of $\mathrm{C} 18: 1$ trans-11. Biohydrogenation of C18:2n-6 and C18:3n-3 was decreased by sucrose inclusion. These changes may be at least partially due to increased abundance of $B$. fibrisolvens, and decreased abundance of $M$. elsdenii.

\section{Abbreviations}

CLA: conjugated linoleic acid; DM: dry matter; FA: fatty acids; MFD: milk fat depression; VFA: volatile fatty acid. 


\section{Competing interests}

The authors declare that they have no competing interests.

\section{Authors' contributions}

XQS participated in the experimental design, carried out of the experimental trial and the paper writing. YPW carried out the whole experimental trial, and helped to draft the manuscripts. BC participated in the sampling and measured rumen fermentation parameters. XZ made crucial contributions to the experimental design and finalized the manuscript. All authors read and approved the final manuscript.

\section{Acknowledgements}

The research was supported by the National Natural Science Foundation of China (Beijing, China; 31402103), the State Key Laboratory of Animal Nutrition (Beijing, China; 2004DA125184F1420) and China Postdoctoral Science Foundation (Beijing, China; 2015M572605).

\section{Received: 13 July 2015 Accepted: 30 November 2015} Published online: 24 December 2015

\section{References}

1. Broderick GA, Luchini ND, Reynal SM, Varga GA, Ishler VA. Effect on production of replacing dietary starch with sucrose in lactating dairy cows. J Dairy Sci. 2008;91(12):4801-10.

2. Vallimont JE, Bargo F, Cassidy TW, Luchini ND, Broderick GA, Varga GA. Effects of replacing dietary starch with sucrose on ruminal fermentation and nitrogen metabolism in continuous culture. J Dairy Sci. 2004;87(12):4221-9.

3. Martel CA, Titgemeyer EC, Mamedova LK, Bradford BJ. Dietary molasses increases ruminal $\mathrm{pH}$ and enhances ruminal biohydrogenation during milk fat depression. J Dairy Sci. 2011;94(8):3995-4004.

4. Penner GB, Oba M. Increasing dietary sugar concentration may improve dry matter intake, ruminal fermentation, and productivity of dairy cows in the postpartum phase of the transition period. J Dairy Sci. 2009;92(7):3341-53.

5. Lee MRF, Merry RJ, Davies DR, Moorby JM, Humphreys MO, Theodorou MK, et al. Effect of increasing availability of water-soluble carbohydrates on in vitro rumen fermentation. Anim Feed Sci Tech. 2003;104(1-4):59-70.

6. Ribeiro CV, Karnati SK, Eastridge ML. Biohydrogenation of fatty acids and digestibility of fresh alfalfa or alfalfa hay plus sucrose in continuous culture. J Dairy Sci. 2005:88(11):4007-17.

7. Sannes RA, Messman MA, Vagnoni DB. Form of rumen-degradable carbohydrate and nitrogen on microbial protein synthesis and protein efficiency of dairy cows. J Dairy Sci. 2002;85(4):900-8.

8. Penner GB, Guan LL, Oba M. Effects of feeding Fermenten on ruminal fermentation in lactating Holstein cows fed two dietary sugar concentrations. J Dairy Sci. 2009;92(4):1725-33.

9. Oba M. Review: Effects of feeding sugars on productivity of lactating dairy cows. Can J Anim Sci. 2011;91(1):37-46.

10. Bauman DE, Harvatine KJ, Lock AL. Nutrigenomics, rumen-derived bioactive fatty acids, and the regulation of milk fat synthesis. Annu Rev Nutr. 2011;31: 299-319.

11. Jenkins TC, Wallace RJ, Moate PJ, Mosley EE. Board-invited review: Recent advances in biohydrogenation of unsaturated fatty acids within the rumen microbial ecosystem. J Anim Sci. 2008;86(2):397-412.

12. Kim YJ, Liu RH, Rychlik JL, Russell JB. The enrichment of a ruminal bacterium (Megasphaera elsdenii YJ-4) that produces the trans-10, cis-12 isomer of conjugated linoleic acid. J Appl Microbiol. 2002;92(5):976-82.

13. Wallace RJ, McKain N, Shingfield KJ, Devillard E. Isomers of conjugated linoleic acids are synthesized via different mechanisms in ruminal digesta and bacteria. J Lipid Res. 2007;48(10):2247-54.

14. Kepler CR, Hirons KP, McNeill JJ, Tove SB. Intermediates and products of the biohydrogenation of linoleic acid by Butyrinvibrio fibrisolvens. J Biol Chem. 1966;241(6):1350-4.

15. Kim YJ, Liu RH, Bond DR, Russell JB. Effect of linoleic acid concentration on conjugated linoleic acid production by Butyrivibrio fibrisolvens A38. App Environ Microbiol. 2000;66(12):5226-30.

16. Fernando SC, Purvis 2nd HT, Najar FZ, Sukharnikov LO, Krehbiel CR, Nagaraja TG, et al. Rumen microbial population dynamics during adaptation to a high-grain diet. Appl Environ Microbiol. 2010;76(22):7482-90.

17. Lee MR, Huws SA, Scollan ND, Dewhurst RJ. Effects of fatty acid oxidation products (green odor) on rumen bacterial populations and lipid metabolism in vitro. J Dairy Sci. 2007;90(8):3874-82.
18. AOAC. Official methods of analysis. 16th ed. Arlington: Assoc. Anal. Chem; 1998.

19. Van Soest PJ, Robertson JB, Lewis BA. Methods for dietary fiber, neutral detergent fiber, and nonstarch polysaccharides in relation to animal nutrition. J Dairy Sci. 1991;74(10):3583-97.

20. Knudsen KEB. Carbohydrate and lignin contents of plant materials used in animal feeding. Anim Feed Sci Tech. 1997;67(4):319-38.

21. Hall MB, Hoover WH, Jennings JP, Webster TKM. A method for partitioning neutral detergent-soluble carbohydrates. J Sci Food Agr. 1999;79(15):2079-86.

22. Khorasani GR, Okine EK, Kennelly JJ. Forage source alters nutrient supply to the intestine without influencing milk yield. J Dairy Sci. 1996;79(5):862-72.

23. Fawcett J, Scott J. A rapid and precise method for the determination of urea. J Clin Pathol. 1960;13(2):156-9.

24. Sun $X Q$, Gibbs SJ. Diurnal variation in fatty acid profiles in rumen digesta from dairy cows grazing high-quality pasture. Anim Feed Sci Tech. 2012; 177(3):152-60.

25. Loor JJ, Ueda K, Ferlay A, Chilliard Y, Doreau M. Biohydrogenation, duodenal flow, and intestinal digestibility of trans fatty acids and conjugated linoleic acids in response to dietary forage : concentrate ratio and linseed oil in dairy cows. J Dairy Sci. 2004;87(8):2472-85.

26. Kittelmann S, Seedorf H, Walters WA, Clemente JC, Knight R, Gordon Jl, et al. Simultaneous amplicon sequencing to explore co-occurrence patterns of bacterial, archaeal and eukaryotic microorganisms in rumen microbial communities. PLoS One. 2013;8(2):e47879.

27. Li F, Li Z, Li S, Ferguson JD, Cao Y, Yao J, et al. Effect of dietary physically effective fiber on ruminal fermentation and the fatty acid profile of milk in dairy goats. J Dairy Sci. 2014;97(4):2281-90.

28. Khalili H, Huhtanen P. Sucrose supplements in cattle given grass silagebased diet. 1. Digestion of organic matter and nitrogen. Anim Feed Sci Technol. 1991;33(3-4):247-61.

29. Oba M, Mewis JL, Zhining Z. Effects of ruminal doses of sucrose, lactose, and corn starch on ruminal fermentation and expression of genes in ruminal epithelial cells. J Dairy Sci. 2015;98(1):586-94.

30. Li RW, Wu S, Baldwin RL, Li W, Li C. Perturbation dynamics of the rumen microbiota in response to exogenous butyrate. PLoS One. 2012;7(1):e29392.

31. Ohkawara S, Furuya H, Nagashima K, Asanuma N, Hino T. Oral administration of butyrivibrio fibrisolvens, a butyrate-producing bacterium, decreases the formation of aberrant crypt foci in the colon and rectum of mice. J Nutr. 2005;135:2878-83.

32. Allison MJ, Bryant MP. Biosynthesis of branched-chain amino acids from branched-chain fatty acids by rumen bacteria. Arch Biochem Biophys. 1963; 101:269-77.

33. Rychlik JL, LaVera R, Russell JB. Amino acid deamination by ruminal Megasphaera elsdenii strains. Curr Microbiol. 2002;45(5):340-5.

34. Kellogg DW. Influence of sucrose on rumen fermentation pattern and milk fat content of cows fed a high-grain ration. J Dairy Sci. 1969;52(10):1601-4.

35. Hall MB, Herejk C. Differences in yields of microbial crude protein from in vitro fermentation of carbohydrates. J Dairy Sci. 2001;84(11):2486-93.

36. Owens FN, Goetsch AL. Ruminal fermentation. In: Church DC, editor. The ruminant animal digestive physiology and nutrition. Prospect Heights: Waveland Pr Inc; 1988. p. 145-71.

37. Or-Rashid MM, Kramer JKG, Wood MA, McBride BW. Supplemental algal meal alters the ruminal trans-18: 1 fatty acid and conjugated linoleic acid composition in cattle. J Anim Sci. 2008;86(1):187-96.

38. Zened A, Enjalbert F, Nicot MC, Troegeler-Meynadier A. Starch plus sunflower oil addition to the diet of dry dairy cows results in a trans-11 to trans-10 shift of biohydrogenationJ. Dairy Sci. 2013;96(1):451-9.

39. Russell JB, Baldwin RL. Substrate preferences in rumen bacteria: evidence of catabolite regulatory mechanisms. Appl Environ Microbiol. 1978;36(2):319-29.

40. Harfoot CG, Hazlewood GP. Lipid metabolsim in the rumen. In: Hobson PN Steward CS, editors. The Rumen Microbial Ecosystem. London: Blackie and Professional; 1997. p. 382-426.

41. McSweeney CS, Denman SE. Effect of sulfur supplements on cellulolytic rumen micro-organisms and microbial protein synthesis in cattle fed a high fibre diet. J Appl Microbiol. 2007;103(5):1757-65.

42. Stevenson DM, Weimer PJ. Dominance of Prevotella and low abundance of classical ruminal bacterial species in the bovine rumen revealed by relative quantification real-time PCR. Appl Microbiol Biotechnol. 2007;75(1):165-74.

43. Shingfield KJ, Kairenius P, Arola A, Paillard D, Muetzel S, Ahvenjarvi S, et al. Dietary fish oil supplements modify ruminal biohydrogenation, alter the flow of fatty acids at the omasum, and induce changes in the ruminal butyrivibrio population in lactating cows. J Nutr. 2012;142(8):1437-48. 